\title{
Prevalence and Association of Criteria of Metabolic Syndrome in a Cohort of Diabetes Type 2 in Saint-Louis
}

\author{
Dia Diatou Gueye ${ }^{1,2}$, Dia Amadou Diop1,2, Diagne Nafissatou3 ${ }^{3}$ M. Ngouamba Blaise2, \\ Ndao Awa Cheikh ${ }^{3}$, Pouye Abdoulaye ${ }^{3}$ \\ ${ }^{1}$ UFR of Health Sciences, Gaston Berger University, Saint Louis, USA \\ ${ }^{2}$ Regional Hospital Center of Saint-Louis, Saint Louis, USA \\ ${ }^{3}$ Cheikh Anta Diop University, Dakar, Senegal \\ Email: diadiami@yahoo.fr
}

How to cite this paper: Gueye, D.D., Diop, D.A., Nafissatou, D., Blaise, M.N., Cheikh, N.A. and Abdoulaye, P. (2019) Prevalence and Association of Criteria of Metabolic Syndrome in a Cohort of Diabetes Type 2 in Saint-Louis. Open Journal of Internal Medicine, 9, 45-51. https://doi.org/10.4236/ojim.2019.93007

Received: June 17, 2019

Accepted: August 2, 2019

Published: August 5, 2019

Copyright ( 2019 by author(s) and Scientific Research Publishing Inc. This work is licensed under the Creative Commons Attribution International License (CC BY 4.0).

http://creativecommons.org/licenses/by/4.0/

\section{(c) (i) Open Access}

\begin{abstract}
Introduction: The metabolic syndrome is characterized by an aggregate of metabolic disorders whose coexistence in the same individual can correspond on the one hand to a common pathophysiological mechanism and on the other hand to expose the subject to an increased risk of cardiovascular diseases. The prevalence of the metabolic syndrome is increasing rapidly in both developed and developing countries, but has been poorly described in sub-Saharan Africa. Most of them reported the components of the metabolic syndrome only in isolation. Methods: This cross-sectional study carried out on a cohort of 76 patients followed at the Sait-louis regional hospital used the definition criteria of the International Diabetes Federation. Results: The average age of our patients is 56.92 with extremes ranging from 32 to 80 years old. The sex ratio is 0.49 . The average duration of diabetes progression is 68 months. The prevalence of the metabolic syndrome in this population is $67.1 \%$. Abdominal obesity and high blood pressure are the most commonly found criteria. Abdominal obesity was the most associated component of MS in both sexes followed by high blood pressure. We found relatively weak data for dyslipidemia, especially hypertriglyceridemia. HypoHD is dyslipidemia more found in our cohort: in $45 \%$ of women and $21 \%$ of men. Conclusion: The management of the metabolic syndrome therefore requires fighting against all the factors that compose it, the first of which is the accumulation of visceral fat. Lifestyle modification is the first priority for these patients facing a society where the reduction of physical activity and the enrichment of the fat diet are becoming more and more important.
\end{abstract}




\section{Keywords}

Diabetes, Dyslipidemia, Abdominal Obesity, Saint-Louis (Senegal)

\section{Introduction}

Type 2 diabetes, a true global pandemic and a public health problem [1] [2] [3] [4] [5], is associated with comorbidities, such as obesity, dyslipidemias, high blood pressure and comorbidities that may be present in the metabolic syndrome. These comorbidities are recognized as cardiovascular risk factors, increasing the morbidity and mortality of patients [6].

This syndrome results from the association of 3 types of alterations: the accumulation of adipose tissue (TA) in particular at the level of the muscle and the liver, leading to a lipotoxicity of free fatty acids (FFA) and their derivatives at the level of these insulin-sensitive organs; alteration of the endocrine function of TA with modification of adipokine production (decrease of insulin-sensitizing adiponectin, increase of adipokines involved in insulin resistance); and macrophage infiltration resulting in the development of a pro-inflammatory state (inappropriate secretion of TNF- $\alpha$ and IL-1) leading to insulin resistance and hyperinsulinism [6] [7] [8].

The growing interest in metabolic syndrome comes from the fact that it predisposes to ischemic cardiovascular disease. In addition, its frequency and severity make it a major public health problem.

The main objective of this study is to determine the prevalence of metabolic syndrome in a population of diabetics followed in northern Senegal. The secondary objectives are to describe the association of the different criteria of the metabolic syndrome.

\section{Methods}

The population of the study is made up of 76 patients received in consultation at the department of internal medicine of the Regional Hospital Center of Saint-Louis from January to July 2018. Inclued all patients diagnosed with type 2 diabetes after free and informed consent.

The study variables were:

- anamnestic: age, sex, lifestyle (sedentary lifestyle, tobacco, physical activity); duration of diabetes;

- clinical course: weight, height, body mass index (BMI), waist circumference;

- biological: total cholesterol, HDL-cholesterol, triglycerides, fasting glucose; HbAlc.

IDF (International Diabetes Federation) criteria were used for the determination of the metabolic syndrome. These criteria include abdominal obesity, defined by waist circumference $>80 \mathrm{~cm}$ in women and $>94 \mathrm{~cm}$ in men and/or a body mass index (BMI) $\geq 30 \mathrm{~kg} / \mathrm{m}^{2}$, and associated with at least two of the fol- 
lowing criteria [9]:

- fasting blood glucose $>1.00 \mathrm{~g} / \mathrm{l}$;

- blood pressure (BP) $\geq 130 / 85 \mathrm{mmHg}$;

- Triglycerides $>1.50 \mathrm{~g} / \mathrm{l}$;

- HDL-cholesterol (HDL-C) $<0.40 \mathrm{~g} / 1$ in men and $<0.50 \mathrm{~g} / 1$ in women.

Patients were classified into three groups, depending on the number of Metabolic Syndrome criteria present.

A systematic clinical examination as well as a compendium of ongoing diabetes treatments was performed in all patients.

\section{Results}

The average age of our patients is 56.92 with extremes ranging from 32 to 80 years old. The sex ratio is 0.49 . The average duration of diabetes progression is 68 months.

The prevalence of metabolic syndrome is $67.1 \%$ and the distribution of metabolic syndrome criteria is shown in Table 1.

Of the components of the metabolic syndrome, abdominal obesity was the most common with $64.4 \%$ followed by $51.3 \%$. The study of type 2 diabetic patients with metabolic syndrome showed:

- $\quad$ an average age of 57.9 years;

- a sex ratio (m/f): 0.41;

- a sedentary lifestyle at $51.31 \%$.

The averages of the different variables by sex are presented in Table 2 and Figure 1.

We did not find a relationship between sex and the presence of the metabolic syndrome (Khi2 $=0.85)$.

Therapeutically, $84 \%$ of the study population are treated with oral antidiabetic agents $(\mathrm{ADO}), 10 \%$ by insulin and the rest by insulin-ADO combination.

Table 1. Frequency of association of metabolic syndrome criteria.

\begin{tabular}{lcc}
\multicolumn{1}{c}{ Métabolic syndrome criteria } & Number & Percentage \% \\
\hline Three criteria (Group 1) & 36 & 70.5 \\
-Diabetes, waist size, Hypertension & 19 & 37.2 \\
-Diabetes, waist size, TG & 1 & 2 \\
-Diabetes, waist size, HDLc & 16 & 31.3 \\
Quatre critères (Group 2) & 14 & 27.4 \\
-Diabetes, waist size, Hypertension, TG & 2 & 3.9 \\
-Diabetes, waist size, Hypertension HDLc & 11 & 21.5 \\
-Diabetes, waist size, TG, HDLc & 1 & 2 \\
Cinq critères (Group 3) & & 2 \\
-Diabetes, waist size, Hypertension, HDLc, TG & 1 & 100 \\
Total & 51 &
\end{tabular}

TG: Triglyceride; HDLc: HDL Cholesterol. 
Table 2. Metabolic syndrome criteria by gender.

\begin{tabular}{lc}
\hline \multicolumn{1}{c}{ Metabolic syndrome criteria } & Average (extremes) \\
\hline Waist size $(\mathrm{cm})$ & $93.2(71-114)$ \\
-Men & $94.91(60-135)$ \\
-Women & \\
BMI $\left(\mathrm{kg} / \mathrm{m}^{2}\right)$ & $23.5(17.3-34.31)$ \\
-Men & $25.1(14.6-46.9)$ \\
-Women & \\
Systolic Blood Pressure (mmHg) & $134.8(100-170)$ \\
-Men & $137.4(100-190)$ \\
-Women & \\
Diastolic Blood Pressure (mmHg) & $82(60-100)$ \\
-Men & $84.5(50-130)$ \\
-Women & \\
Triglycerides $(\mathrm{g} / \mathrm{l})$ & $0.94(0.33-2.53)$ \\
-Men & $0.88(0.2-2.46)$ \\
-Women & \\
HDLc (g/l) & $0.45(0.27-0.86)$ \\
-Men & $0.52(0.11-1.21)$ \\
-Women &
\end{tabular}

BMI: Body Mass Index; HDLc: HDL Cholesterol.

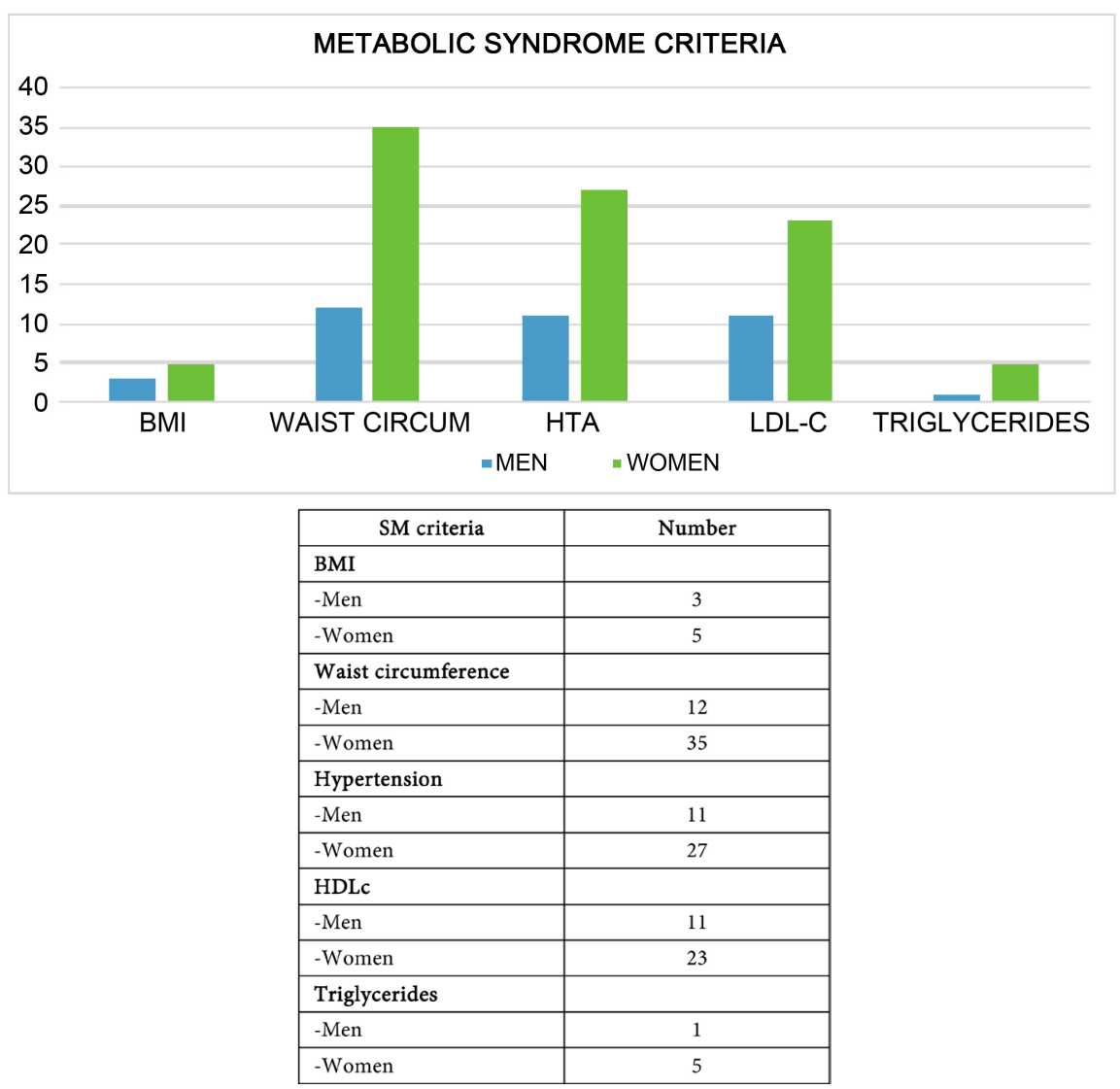

Figure 1. Number of metabolic syndrome variables by sex. 


\section{Discussion}

In our study, $67 \%$ of diabetic patients met the FID criteria of the metabolic syndrome. The comparison of prevalence levels by country in different studies is biased by the variety of definitions used. While the definitions agree on the essential components of the MS, they differ on the critical values used for each of its components and on the combinations of criteria used to define the MS.

However, regardless of the definition used for the prevalence assessment of $\mathrm{DM}$, the results highlight a high prevalence of this syndrome in developed countries, as well as a significant increase in developing countries [1] [2] [3] [5]. In Africa, it is difficult to assess, in the current state of knowledge, the prevalence of the metabolic syndrome. With the exception of a few countries, namely Algeria and South Africa, where studies on the metabolic syndrome have been carried out [10] [11], most other countries do not.

A survey conducted in the Abidjan general population found $5 \%$ of metabolic syndrome [12]. In a second comparative Ivorian study, 38\% of metabolic syndrome was observed in diabetics compared with $2 \%$ in non-diabetics [13].

In Guinea, Diallo et al. found a prevalence of $56 \%$ in a cohort of type 2 diabetics closer to our results [14] [15].

In our population, obesity and high blood pressure are the defining criteria for the metabolic syndrome most commonly associated with type 2 diabetes.

Monabeka reported that abdominal obesity was the most associated component of MS in both sexes [16].

Doupa et al. reveals, in a study made in the general population of Saint-Louis, $25 \%$ of obesity $\left(\mathrm{BMI}>30 \mathrm{~kg} / \mathrm{m}^{2}\right)$ and $34.8 \%$ of abdominal obesity [17].

Classically, dyslipidemia in type 2 diabetes is characterized by both quantitative and qualitative lipoprotein abnormalities with, typically, a moderate increase in plasma triglycerides (TG), a variable lowering of HDL-cholesterol (HDL-c). and an accumulation of residual lipoproteins enriched in cholesterol (remnants) [18].

HypoHDLemia is dyslipidemia is more found in our cohort: in $45 \%$ of women and $21 \%$ of men. Our figures are close to those described by concordance with the data of Fezeu et al. in Cameroon [19].

\section{Conclusions}

Our work confirms the high prevalence of metabolic syndrome in sub-Saharan Africa and particularly in type 2 diabetics.

This syndrome must be systematically detected in daily practice and awareness campaigns on the cardiovascular risks related to this syndrome must be undertaken, in order to inform and sensitize our populations to a better lifestyle.

\section{Conflicts of Interest}

The authors declare no conflicts of interest regarding the publication of this paper. 


\section{References}

[1] Ford, E.S., Giles, W. and Dietz, W. (2002) Prevalence of the Metabolic Syndrome among U.S. Adults: Findings from the Third National Health and Nutrition Examination Survey. JAMA, 287, 356-359. https://doi.org/10.1001/jama.287.3.356

[2] Ford, E.S. (2005) Prevalence of the Metabolic Syndrome Defined by the International Diabetes Federation among Adults in the U.S. Diabetes Care, 28, 2745-2749. https://doi.org/10.2337/diacare.28.11.2745

[3] Gami, A.S., Witt, B.J., Howard, D.E., et al. (2007) Metabolic Syndrome and Risk of Incident Cardiovascular Events and Death: A Systematic Review and Meta-Analysis of Longitudinal Studies. Journal of the American College of Cardiology, 49, 403-414. https://doi.org/10.1016/j.jacc.2006.09.032

[4] Ducluzeau, P.H. (2006) Le Metabolic syndrom in 2006 Medecine du Sommeil Année 3 Octobre Novembre Décembre. https://doi.org/10.1016/S1769-4493(06)70081-4

[5] Cornier, M.A., Dabelea, D., Hernandez, T.L., Lindstrom, R.C., Steig, A.J., Stob, N.R., et al. (2008) The Metabolic Syndrome. Endocrine Reviews, 29, 777-822. https://doi.org/10.1210/er.2008-0024

[6] Despres, J.P. and Lemieux, I. (2006) Abdominal Obesity and Metabolic Syndrome. Nature, 444, 881-887. https://doi.org/10.1038/nature05488

[7] Lakka, H.M., Laaksonen, D.E., Lakka, T.A., Niskanen, L.K., Kumpusalo, E., Tuomilehto, J., et al. (2002) The Metabolic Syndrome and Total and Cardiovascular Disease Mortality in Middle-Aged Men. JAMA, 288, 2709-2716. https://doi.org/10.1001/jama.288.21.2709

[8] Kim, J.A., Montagnani, M., Koh, K.K. and Quon, M.J. (2006) Reciprocal Relationships between Insulin Resistance and Endothelial Dysfunction: Molecular and Pathophysiological Mechanisms. Circulation, 113, 1888-1904. https://doi.org/10.1161/CIRCULATIONAHA.105.563213

[9] Alberti, K.G., Zimmet, P. and Shaw, J. (2005) IDF Epidemiology Task Force Consensus Group. The Metabolic Syndrome-A New Worldwide Definition. The Lancet, 366, 1059-1062. https://doi.org/10.1016/S0140-6736(05)67402-8

[10] Guize, L., Thomas, F., Pannier, B., Bean, K., Jego, B. and Benetos, A. (2007) All-Cause Mortality Associated with Specific Combinations of the Metabolic Syndrome According to Recent Definitions. Diabetes Care, 30, 2381-2387. https://doi.org/10.2337/dc07-0186

[11] Ker, J., Rheeder, P. and van Tonder, R. (2007) Frequency of Metabolic Syndrome in Screened South African Corporate Executives. Cardiovascular Journal of South Africa, 18, 30-33.

[12] Lokrou, A. (1998) Hyperlipidémia and diabete in Côte d'Ivoire: Transversal study of 132 cas. Medecine d Afrique Noire, 45, 555-557.

[13] Hauhouot-Attoungbre, M.L., Yayo, S.E., Ake-Edjeme, A., et al. (2008) Does métabolic syndrome exist in Côte d'Ivoire? Immuno-analyse \& Biologie Spécialisée, 23, 375-378. https://doi.org/10.1016/j.immbio.2008.10.002

[14] Diallo, A.-M., Diallo, M.-M., Baldé, N.-M., Diakité, M., Baldé, T.-A., Bah, A., Kaké, A., Camara, A., Bah, N.-M. and Lokrou, A. (2012) Prevalence et association of metabolic syndrom métabolic in a type 2 diabetic population in Guinée. Médecine des maladies Métaboliques, 6, 542-545.

[15] Baldé, N.M., Diallo, T.S., Diallo, A.M., Kaké, A., Camara, A., Baldé, T.A., Baldé, M.C., Diallo, A.O., Barry, A.Y., Camara, M.O.N., Camara, I.V., Bah, N.M.T., Diallo, 
M., Youla, C., Bah, D. and Diallo, I. (2010) Metabolic Syndrom and Diabete en Guinéa. Diabetes \& Metabolism, 36, A40-A109.

[16] Monabéka, H.-G., Kimbally-Kaky, G., Gombet, T., Moussounda-Kissama, F. and Banzouzi, B. (2012) Damba Metabolic Syndrom and Prevalence of Ischemic Cardiopathies in CHU de Brazzaville, Congo. Médecine des maladies Métaboliques, 6, 75-79.

[17] Doupa, D., et al. (1937) Lipid Profile Frequency and the Prevalence of Dyslipidaemia from Biochemical Tests at Saint Louis University Hospital in Senegal. Pan African Medical Journal, 17, 75.

[18] Passmore, R. and Durnin, J.W.G.A. (2006) Nutrition du sportif. In: Brunet-Guedj, E., Brunet, B., Girardier, J. and Moyen, B., Eds., Médecine du sport, Masson, Paris, 325-348.

[19] Fezeu, L.K., Assah, F.K., Balkau, B., et al. (2008) Ten-Year Changes in Central Obesity and BMI in Rural and Urban Cameroon. Obesity (Silver Spring), 16, 1144-1147.

https://doi.org/10.1038/oby.2008.44 